\title{
Nuclear Phosphatidylcholine and Sphingomyelin Metabolism of Thyroid Cells Changes during Stratospheric Balloon Flight
}

\author{
Elisabetta Albi, ${ }^{1}$ Samuela Cataldi, ${ }^{1}$ Maristella Villani, ${ }^{2}$ and Giuseppina Perrella ${ }^{3}$ \\ ${ }^{1}$ Department of Clinical and Experimental Medicine, Physiopathology Section, School of Medicine University of Perugia, \\ 06100 Perugia, Italy \\ ${ }^{2}$ Polispecialistica Bios, 88900 Crotone, Italy \\ ${ }^{3}$ Department of Experimental and Clinical Pathology and Medicine, University of Udine, 33100 Udine, Italy \\ Correspondence should be addressed to Elisabetta Albi, ealbi@unipg.it
}

Received 2 July 2009; Accepted 16 September 2009

Recommended by Yusuf Hannun

\begin{abstract}
Nuclear sphingomyelin and phosphatidylcholine metabolism is involved in the response to ultraviolet radiation treatment in different ways related to the physiological state of cells. To evaluate the effects of low levels of radiation from the stratosphere on thyroid cells, proliferating and quiescent FRTL-5 cells were flown in a stratospheric balloon (BIRBA mission). After recovery, the activity of neutral sphingomyelinase, phosphatidylcholine-specific phospholipase $\mathrm{C}$, sphingomyelin synthase, and reverse sphingomyelin synthase was assayed in purified nuclei and the nuclei-free fraction. In proliferating FRTL-5, space radiation stimulate nuclear neutral sphingomyelinase and reverse sphingomyelin synthase activity, whereas phosphatidylcholine-specific phospholipase $\mathrm{C}$ and sphingomyelin synthase were inhibited, thus inducing sphingomyelin degradation and phosphatidylcholine synthesis. This effect was lower in quiescent cells. The possible role of nuclear lipid metabolism in the thyroid damage induced by space radiations is discussed.
\end{abstract}

Copyright () 2009 Elisabetta Albi et al. This is an open access article distributed under the Creative Commons Attribution License, which permits unrestricted use, distribution, and reproduction in any medium, provided the original work is properly cited.

\section{Introduction}

Depletion of ozone in the stratosphere has resulted in an enrichment of ultraviolet (UV) radiation content and global warming $[1,2]$. It has been demonstrated that UV induces the formation of free radicals and reactive oxygen species [3] which can participate in a number of pathological processes including DNA damage and lipid peroxidation [4] as well as hyperchromicity and sensitivity to nuclease S1 digestion of mitochondrial DNA [5]. The harmful effects of UV excess as a consequence of depletion of the stratospheric ozone including the raise in skin cancer incidences [6]. In fact, it is known that exposure of the skin to UV is the main cause of skin cancer development [7] and the tumor suppressor p53 protects the skin by stimulating the tanning response [8]. Moreover, UV exposure was observed to suppress cellmediated immunity in human subjects [9]. Currently, no data exist about the effect of the stratosphere on thyroid cells. In the laboratory, a rat thyroid cell line (FRTL-5) was sensitive to UV radiation when the cells were in the proliferative state whereas quiescent cells were UV resistant and therefore protected from the induction of apoptosis [10]. These differing responses to UV radiation were associated with diverse modifications in nuclear lipid metabolism [10]. Nuclear lipids are quickly metabolised owing to the presence of enzymes related to their metabolism such as phosphatidylcholine specific-phospholipase C (PC-PLC), neutral sphingomyelinase (N-SMase), sphingomyelin synthase (SM synthase), and reverse sphingomyelin synthase (RSM synthase) [11]. In rat liver, these enzyme activities change in relation to the cell proliferation and/or apoptosis [11], an observation that was also evident in rat thyroid, albeit with different results [10]. Furthermore, in nuclei purified from FRTL-5 proliferating cells, UV-C irradiation stimulated $\mathrm{N}$-SMase activity and inhibited SM-synthase and PC-PLC with a consequent increase in the ceramide/diacylglycerol ratio. Notably, this effect was lower in nuclei from quiescent cells. Thus, UV-C radiation induced apoptosis by modifying nuclear lipid metabolism and this varied in relation to the physiological state of cells [10]. Accordingly, the aim of the present paper was to study the effect of stratosphere on nuclear SM and PC metabolism in proliferating and 
quiescent thyroid cells. To achieve this, stratospheric balloons were used to expose biological samples to radiation present at $30-40 \mathrm{~km}$ altitude for approximately 20 hours [12].

\section{Materials and Methods}

2.1. Reagents. PC, SM, and PMSF were obtained from Sigma Chemical Co. (St. Louis, Missouri, U.S.A.); TLC plates (silica Gel G60) were from Merck (Darmstadt, Germany); the radioactive $\mathrm{SM}$ (choline-methyl ${ }^{14} \mathrm{C}, 54.5 \mathrm{Ci} / \mathrm{mol}$ ) and $\mathrm{PC}$ (L-3-phosphatidyl N-methyl- ${ }^{3} \mathrm{H}$ choline 1, 2 dipalmitoyl, 81.0 Ci/mmol) were from Amersham Pharmacia Biotech (Rainham, Essex, UK); Ecoscint A was from National Diagnostic (Atlanta, Georgia, U.S.A.).

2.2. Cell Cultures. Rat FRTL-5 cells were prepared and characterised as previously reported [10]. Cells were grown in Ham's modified F-12 supplemented with 5\% calf serum and the following hormones: $10 \mathrm{ng} / \mathrm{ml}$ glycil-l-histidyl-l-lysine acetate (Sigma), $10^{-8} \mathrm{M}$ hydrocortisone (Sigma), $10 \mu \mathrm{g} / \mathrm{ml}$ insulin (Sigma), $10 \mu \mathrm{g} / \mathrm{ml}$ somatostatin (Sigma), $5 \mu \mathrm{g} / \mathrm{ml}$ transferrin (Sigma), and $10 \mathrm{mU} / \mathrm{ml} \mathrm{TSH} \mathrm{(Sigma).} \mathrm{FRTL5}$ were maintained at $37^{\circ} \mathrm{C}$ in $5 \%$ of $\mathrm{CO}_{2}$, and $95 \%$ humidity. For the experiments, proliferating cells were cultured in the presence of TSH, whereas quiescent cells were cultured without TSH [10].

2.3. Flight of Stratospheric Balloon BIRBA Mission. For flight of the "Stratospheric Balloon BIRBA Mission", FRTL5 cells cultured in the presence or in absence of TSH were placed for 24 hours into two identical types of thermostated incubator containers, of which one contained a shield to protect cells from space radiation. The shielding of the box was developed by Zanini et al. [13]. During the mission, radiation spectra were measured in both incubators, while temperature, pressure, and altitude were continuously monitored and recorded by a data logger as reported [12]. These parameters were controlled by Kayser-Italia, Livorno. The total radiation measured was $11.23 \mathrm{mSv} / \mathrm{h}$, the radiation in the shielded box was $50 \%$ of that in the normal box for all components except the neutrons [12]. The Stratospheric Balloon left by Milo (launch site of Trapani-Italy) to arrive to Siviglia (baseSpanish). After landing, samples were retrieved within 12 hours, medium was removed and the FRTL5 cells collected, centrifuged and frozen at $-80^{\circ} \mathrm{C}$. Control samples were maintained in normal incubators under the same physiologic conditions.

2.4. DNA Ladder. Apoptotic cell death was analyzed by DNA ladder as previously reported [14].

2.5. Nuclei Free Lysates and Nuclei Preparation. Nuclei-free lysate (NFL) and purified nuclei were prepared as previously reported [10].

2.6. Protein Determinations. Protein determination was made as previously reported [10].
2.7. Neutral-Sphingomyelinase Assay. The N-SMase activity was detected as previously reported [10]. In reactions, $1.6 \mathrm{nmol}$ of ${ }^{14} \mathrm{C}-\mathrm{SM}$ was diluted by adding $78.4 \mathrm{nmol}$ cold SM (final specific activity $1.08 \mathrm{Ci} / \mathrm{mol}$ ). The reaction mixture contained $0.1 \mathrm{M}$ Tris/ $\mathrm{HCl} \mathrm{pH} 7.6,0.1 \mathrm{mM}-{ }^{14} \mathrm{C} \mathrm{SM}$, $6 \mathrm{mM} \mathrm{MgCl}_{2}, 0.1 \%$ Triton X-100, and $100 \mu \mathrm{g}$ protein of NFL or nuclei to a final volume of $0.1 \mathrm{ml}$. Incubations were performed at $37^{\circ} \mathrm{C}$ for 45 minutes. The reaction was stopped by adding $2 \mathrm{ml}$ chloroform and methanol (2:1); $0.4 \mathrm{ml}$ of $0.5 \% \mathrm{NaCl}$ was added to the tubes and vortexed. After centrifugation at $2000 \mathrm{RPM} \times 10$ minutes, the upper phase was removed and $0.5 \mathrm{ml}$ was used for radioactivity measurement with a Packard liquid scintillation analyzer.

2.8. Phosphatidylcholine-Specific Phospholipase C Assay. The PC-PLC activity was detected as previously reported [10]. In the reactions, $0.31 \mathrm{pmol}$ of ${ }^{3} \mathrm{H}-\mathrm{PC}$ was diluted by adding $19.69 \mathrm{nmol}$ cold PC to a final specific activity $1.27 \mathrm{Ci} / \mathrm{mol}$. The reaction mixture contained $0.1 \mathrm{M}$ Tris- $\mathrm{HCl}, 0.3 \mathrm{mM}{ }^{3} \mathrm{H}$ PC, $2 \mathrm{mM} \mathrm{CaCl}_{2}, 0.1 \%$ Triton $\mathrm{X}-100$, and $100 \mu \mathrm{g}$ protein of NFL or nuclei, to a final volume of $0.1 \mathrm{ml}$. Incubations were performed at $37^{\circ} \mathrm{C}$ for 45 minutes. The reaction was stopped by adding $2 \mathrm{ml}$ chloroform and methanol (2:1); $0.4 \mathrm{ml}$ of $0.5 \% \mathrm{NaCl}$ was added to the tubes and vortexed. After centrifugation at $2000 \mathrm{RPM} \times 10$ minutes, the upper phase was removed and $0.5 \mathrm{ml}$ was used for radioactivity measurement as reported for N-SMase assay.

2.9. Sphingomyelin-Synthase Assay. Enzymatic activity was detected as previously reported [10]. The reaction mixture, temperature, and incubation time were the same as for PCPLC activity but $0.15 \mathrm{mM}$ nonhydroxy fatty acid ceramide was added. After centrifugation, the lower phase was dried under nitrogen flow, lipids were resuspended with chloroform and separated with thin-layer silica gel chromatography (TLC), using chloroform/methanol/ammonia (65: $25: 4$ ) as solvent. In the sample, exogenous SM was added to the tubes before chromatography. SM was localized with iodine vapour, scraped into counting vials and diluted with $10 \mathrm{ml}$ Ecoscint $\mathrm{A}$ and $1 \mathrm{ml}$ water. Radioactivity was measured as reported for N-SMase activity.

2.10. Reverse Sphingomyelin-Synthase Assay. Enzymatic activity was detected as previously reported [10]. The reaction mixture temperature and incubation time were the same as for SMase activity but $0.3 \mathrm{mM}$ dipalmotoyl glycerol DAG was added. After centrifugation, the lower phase was dried under nitrogen flow, lipids were resuspended with chloroform and separated as described above for SM-synthase. In the sample, exogenous PC was added to tubes before chromatography. PC was localized with iodine vapour, scraped into counting vials and diluted with $10 \mathrm{ml}$ Ecoscint $\mathrm{A}$ and $1 \mathrm{ml}$ water. Radioactivity was measured as described for N-SMase activity.

2.11. Statistical Analysis. Means \pm SD are given. The significance of the differences between the data was checked by ANOVA. 


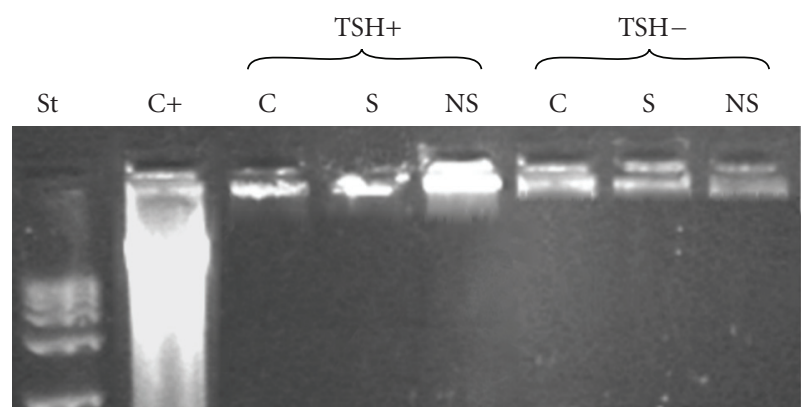

Figure 1: DNA ladder in control and shielded and no-shielded FTRL- 5 cells cultured in the presence of TSH (TSH+) or after TSH starvation $(\mathrm{TSH}-)$. $\mathrm{St}=$ standard; $\mathrm{C}+=$ positive control obtained in $\mathrm{TSH}+$ cells treated with UV-C radiations $\left(254 \mathrm{~nm}, 20 \mathrm{~J} / \mathrm{m}^{2}\right.$ radiation fluence rate from a low-pressure mercury lamp for two seconds); C $=$ control; $\mathrm{S}=$ shielded NS $=$ no shielded .

\section{Results}

\subsection{Effect of Stratosphere on Proliferating and Quiescent} Thyroid Cells. The presence of TSH in the culture medium stimulated proliferation of FTRL-5 cells whereas cells cultured without TSH remained in the quiescent state [10]. As it is not possible to study the cells directly during the 24hour stratospheric balloon space mission, cell analysis was performed on cells frozen after recovery (12 hours). Therefore, results were an expression of the complete mission. Analysis of the DNA ladder by gel electrophoresis showed that neither proliferating nor quiescent cells presented with DNA fragmentation (Figure 1). In contrast, lipid metabolism was strongly modified. In the nuclei-free lysate (NFL) of the $\mathrm{TSH}+$ cells maintained without shielding, N-SMase activity was increased 4.18-fold and PC-PLC activity was reduced 2.39-fold by the stratospheric mission with no change in SM-synthase or RSM-synthase activity observed (Figure 2). In purified nuclei from the same cells, the stratospheric mission increased N-SMase and RSM-synthase activities by 7.57 and 2.66-fold, respectively, whereas PC-PLC and SM-synthase activities were reduced by 1.8 and 2.8 -fold, respectively (Figure 3 ). Shielding of the cells protected them from the observed variations in lipid metabolism. In fact, in the NFL, N-SMase activity increased 2.63-fold and PCPLC activity was reduced 1.56 -fold with no change in SMsynthase or RSM-synthase activity (Figure 2). Similarly, in the purified nuclei, N-SMase and RSM-synthase activities increased 3.53 and 2.00-fold, respectively, whereas PC-PLC and SM-synthase activity were reduced 1.15 and 1.55-fold, respectively, in comparison with control samples (Figure 3).

The NFL fraction of TSH- cells maintained without shielding had N-SMase activity increased by 3.20 fold and PC-PLC activity reduced by 1.60 -fold with no change in SM-synthase or RSM-synthase activity (Figure 2). In purified nuclei from the same cells, N-SMase and RSM-synthase activities increased by 10.51 and 2.61-fold, respectively, whereas PC-PLC and SM-synthase activities decreased by 1.42 and 1.37-fold, respectively, (Figure 3). In TSH- cells maintained with shielding, the NFL had increased N-SMase
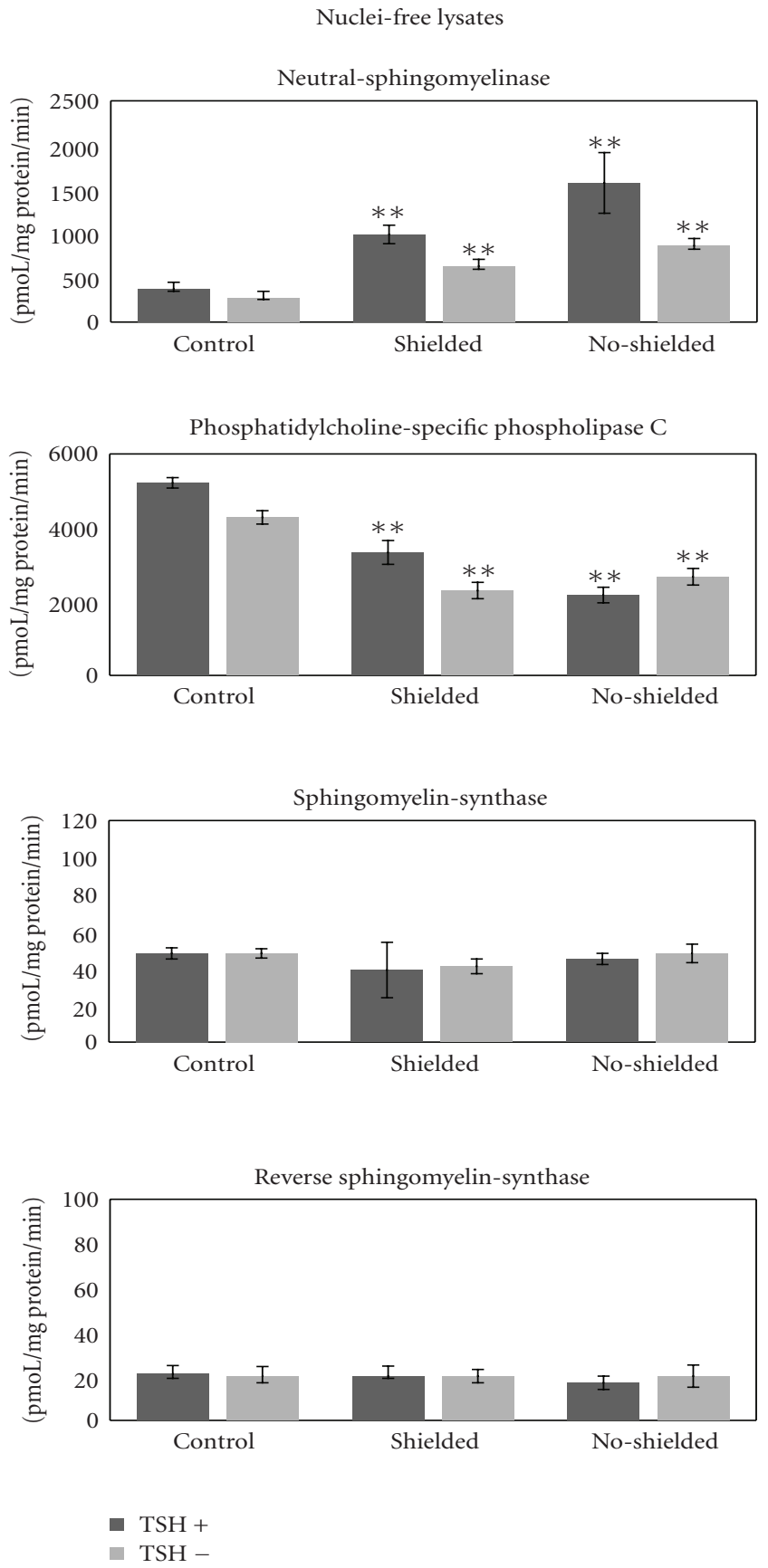

FIGURE 2: Neutral-sphingomyelinase, phosphatidylcholinespecific phospholipase C, sphingomyelin-synthase, and reverse sphingomyelin-synthase activities in purified nuclei of FRTL-5 cell cultured in the presence of TSH (TSH+). Data are expressed as $\mathrm{pmol} / \mathrm{mg}$ protein $/ \mathrm{min}$ and are the mean \pm S.D. of three samples performed in duplicate. ${ }^{* *} P<.001$ versus control sample.

activity (2.34-fold) and reduced PC-PLC activity (1.26fold) with no change in SM-synthase or RSM-synthase activity (Figure 2 ). In the purified nuclei, N-SMase and RSM-synthase activities increased by 8.17 and 1.88 -fold, respectively, whereas PC-PLC activity was reduced by 1.22 fold and SM-synthase activity did not change with respect to the control samples (Figure 3). 
Nuclei
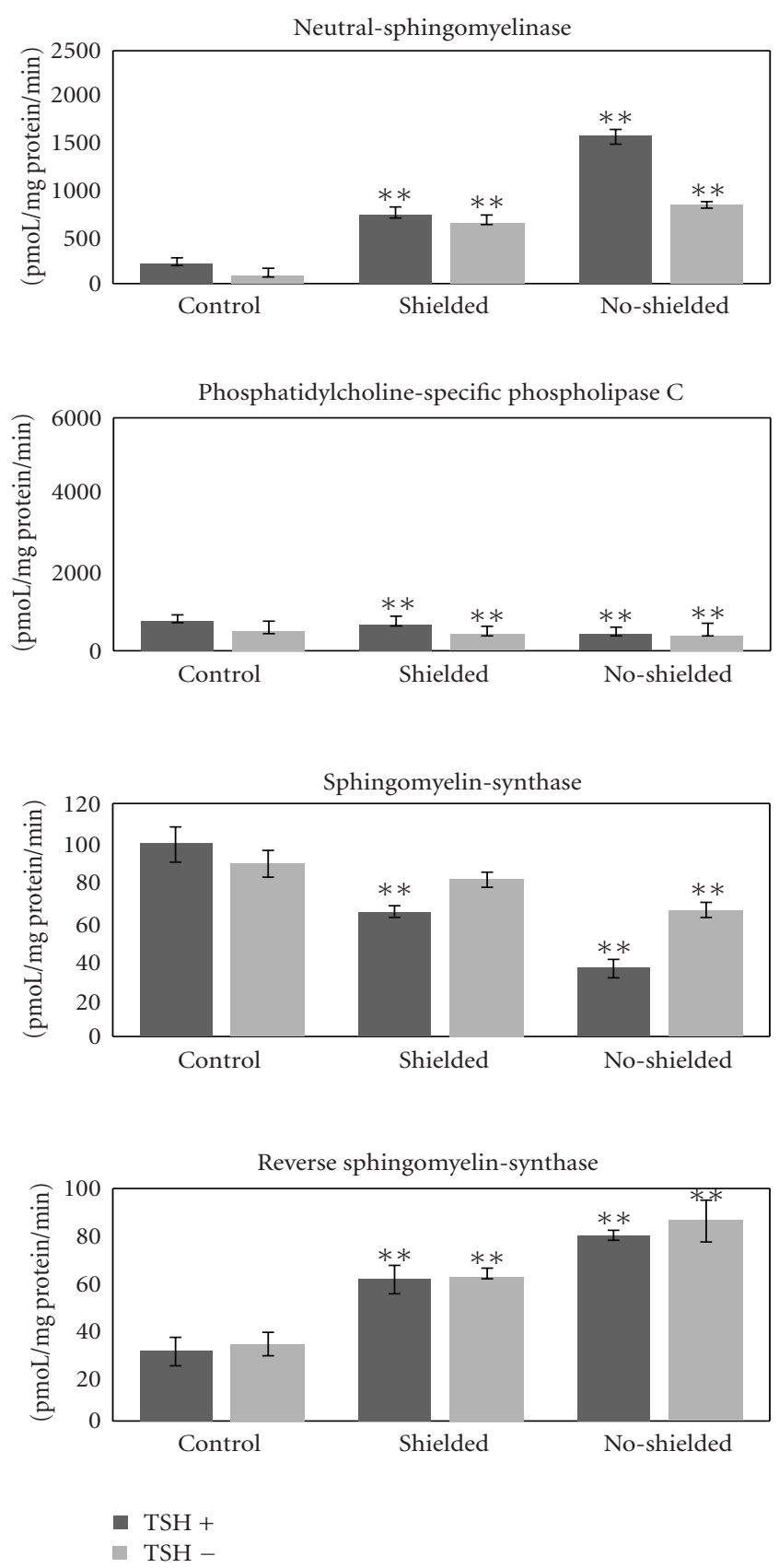

FIGURE 3: Neutral-sphingomyelinase, phosphatidylcholinespecific phospholipase C, sphingomyelin-synthase, and reverse sphingomyelin-synthase activities in purified nuclei of FRTL-5 cell cultured in the presence of TSH (TSH+). Data are expressed as $\mathrm{pmol} / \mathrm{mg}$ protein $/ \mathrm{min}$ and are the mean \pm S.D. of three samples performed in duplicate. ${ }^{* *} P<.001$ versus control sample.

\section{Discussion}

Our results showed clearly that, following the stratospheric balloon mission, FRTL-5 cells did not present with signs of DNA fragmentation characteristic of apoptotic process but, in contrast, have profoundly altered lipid metabolism. These data highlighted the activation of N-SMase and inhibition of PC-PLC in NFL and the activation of N-SMase and RSM-synthase and inhibition of PC-PLC and SM-synthase in purified nuclei. Considering that N-SMase and RSMsynthase enrich the ceramide pool whereas PC-PLC and SMsynthase enrich the DAG pool [15], it is possible that the stratospheric mission induced an increase of ceramide/DAG ratio as was observed for the same cells when treated by UV-C radiation [10]. Proliferating cells were more sensitive to UV-C radiation treatment than quiescent cells. In fact, 48 hours after irradiation, TSH+ cells showed strong DNA fragmentation whereas TSH - cells presented only with low DNA fragmentation albeit with diverse modifications in lipid metabolism [10]. However, the dose of radiation to which cells were exposed during the balloon flight was very low while the treatment with UV in the laboratory provided higher radiation dose [10]. Usually low doses induce a cell adaptation and resistance, while at higher doses cell division was delayed and repair systems were activated, and very high doses cause apoptosis [16, 17]. The effect of UV-C irradiation on lipid metabolism was higher in the nucleus than in NFL [10] and these data are supported in the present paper as there was also a particular involvement of PC and SM metabolism in the nucleus following the stratospheric mission. Notably, a crosstalk between these lipids in the nucleus has been recently described [15]. The effect of the stratospheric mission on the cells was dependent on their physiological state, being stronger in proliferating than in quiescent cells. Shielding of the box containing the cells diminished the effect of the stratosphere and reduced the variations in lipid metabolism. The effect of the shielding was also demonstrated in a study performed on $X$. laevis that participated to the same space mission [12]. The authors demonstrated that the effect of stratosphere depended on the stage of $X$. laevis development. In fact younger embryos were the most affected, with increases in mortality and malformations [12]. Moreover, no induction of HSPs was observed, suggesting that results obtained were caused by the radiation itself and not by general stress occasioned by the balloon flight [12]. It has been recently demonstrated that sphingolipids regulated FRTL-5 cell fate [18]. Here, we demonstrate for the first time that the modification of PC and SM metabolism in FRTL-5 cells during flight at $40 \mathrm{~km}$ altitude changed in relation to the physiological state of the cells without induction of cell death. We used FRTL-5 cells since they are a strain of normal and differentiated rat follicular thyroid cells that in vitro permanently express most in vivo tissue-specific thyroid characteristics, such as thyroglobulin synthesis and secretion, iodide active transport, peroxidase production, and TSH sensitivity and therefore represent a very good model to study the human thyroid physiology [19]. The possibility that low doses of stratospheric radiations induce modifications of thyroid cell function which, in part, could be recovered after the return to earth cannot be excluded. Possible further missions could be used to test the lipid metabolism after a period of adjustment following the return to earth. The identification of the activation of lipid metabolism is a sign that the cells responded to radiation. 


\section{Acknowledgments}

The author thank E. Damascopoulou, M. Peverini, and A. Lazzarini for the technical assistance. This work was supported by grants from Agenzia Spaziale Italiana (ASI), Ministero dell' Università e Ricerca (PRIN project), and Fondazione "Cassa di Risparmio Perugia".

\section{References}

[1] G. A. Francis, E. Fayard, F. Picard, and J. Auwerx, "Nuclear receptors and the control of metabolism," Annual Review of Physiology, vol. 65, pp. 261-311, 2003.

[2] R. Bhandari and P. K. Sharma, "Effect of UV-B and high visual radiation on photosynthesis in freshwater (Nostoc spongiaeforme) and marine (Phormidium corium) cyanobacteria," Indian Journal of Biochemistry \& Biophysics, vol. 44, pp. 231239, 2007.

[3] A. Anwar, M. Gu, S. Brady, et al., "Photoprotective effects of bucillamine against UV-induced damage in an SKH-1 hairless mouse model," Photochemistry and Photobiology, vol. 84, no. 2, pp. 477-483, 2008.

[4] C. S. Sander, F. Hamm, P. Elsner, and J. J. Thiele, "Oxidative stress in malignant melanoma and non-melanoma skin cancer," British Journal of Dermatology, vol. 148, no. 5, pp. 913-922, 2003.

[5] K. Alam, Moinuddin, and S. Jabeen, "Immunogenicity of mitochondrial DNA modified by hydroxyl radical," Cellular Immunology, vol. 247, no. 1, pp. 12-17, 2007.

[6] F. R. de Gruijl, "Skin cancer and solar UV radiation," European Journal of Cancer, vol. 35, no. 14, pp. 2003-2009, 1999.

[7] K. Rass and J. Reichrath, "UV damage and DNA repair in malignant melanoma and nonmelanoma skin cancer," Advances in Experimental Medicine and Biology, vol. 624, pp. 162-178, 2008.

[8] M. Oren and J. Bartek, "The sunny side of p53," Cell, vol. 128, no. 5, pp. 826-828, 2007.

[9] M. Norval, P. McLoone, A. Lesiak, and J. Narbutt, "The effect of chronic ultraviolet radiation on the human immune system," Photochemistry and Photobiology, vol. 84, no. 1, pp. 19-28, 2008.

[10] E. Albi, S. Cataldi, G. Rossi, et al., "The nuclear ceramide/diacylglycerol balance depends on the physiological state of thyroid cells and changes during UV-C radiationinduced apoptosis," Archives of Biochemistry and Biophysics, vol. 478, no. 1, pp. 52-58, 2008.

[11] E. Albi and M. P. Viola Magni, "The role of intranuclear lipids," Biology of the Cell, vol. 96, no. 8, pp. 657-667, 2004.

[12] A. M. Rizzo, F. Rossi, S. Zava, et al., "Antioxidant metabolism in Xenopus laevis embryos is affected by stratospheric balloon flight," Cell Biology International, vol. 31, no. 7, pp. 716-723, 2007.

[13] A. Zanini, C. Ongaro, and L. Tommasino, "Neutron spectrometry at various altitudes. Atmosphere by passive detector technique," Il Nuovo Cimento, vol. 24, pp. 691-767, 2001.

[14] E. Del Terra, A. Francesconi, D. Donnini, F. Curcio, and F. S. Ambesi-Impiombato, "Thyrotropin effects on ultraviolet radiation-dependent apoptosis in FRTL-5 cells," Thyroid, vol. 13, no. 8, pp. 747-753, 2003.

[15] E. Albi, R. Lazzarini, and M. Viola Magni, "Phosphatidylcholine/sphingomyelin metabolism crosstalk inside the nucleus," Biochemical Journal, vol. 410, no. 2, pp. 381-389, 2008.
[16] M. D. Temple, G. G. Perrone, and I. W. Dawes, "Complex cellular responses to reactive oxygen species," Trends in Cell Biology, vol. 15, no. 6, pp. 319-326, 2005.

[17] G. W. Thorpe, C. S. Fong, N. Alic, V. J. Higgins, and I. W. Dawes, "Cells have distinct mechanisms to maintain protection against different reactive oxygen species: oxidativestress-response genes," Proceedings of the National Academy of Sciences of the United States of America, vol. 101, no. 17, pp. 6564-6569, 2004.

[18] Y. Satoh, X. Li, H. Yokota, et al., "Regulation by sphingolipids of the fate of FRTL-5 cells," Journal of Biochemistry, vol. 145, no. 1, pp. 31-36, 2009.

[19] F. S. Ambesi-Impiombato, L. A. M. Parks, and H. G. Coon, "Culture of hormone-dependent functional epithelial cells from rat thyroids," Proceedings of the National Academy of Sciences of the United States of America, vol. 77, pp. 3455-3459, 1980. 

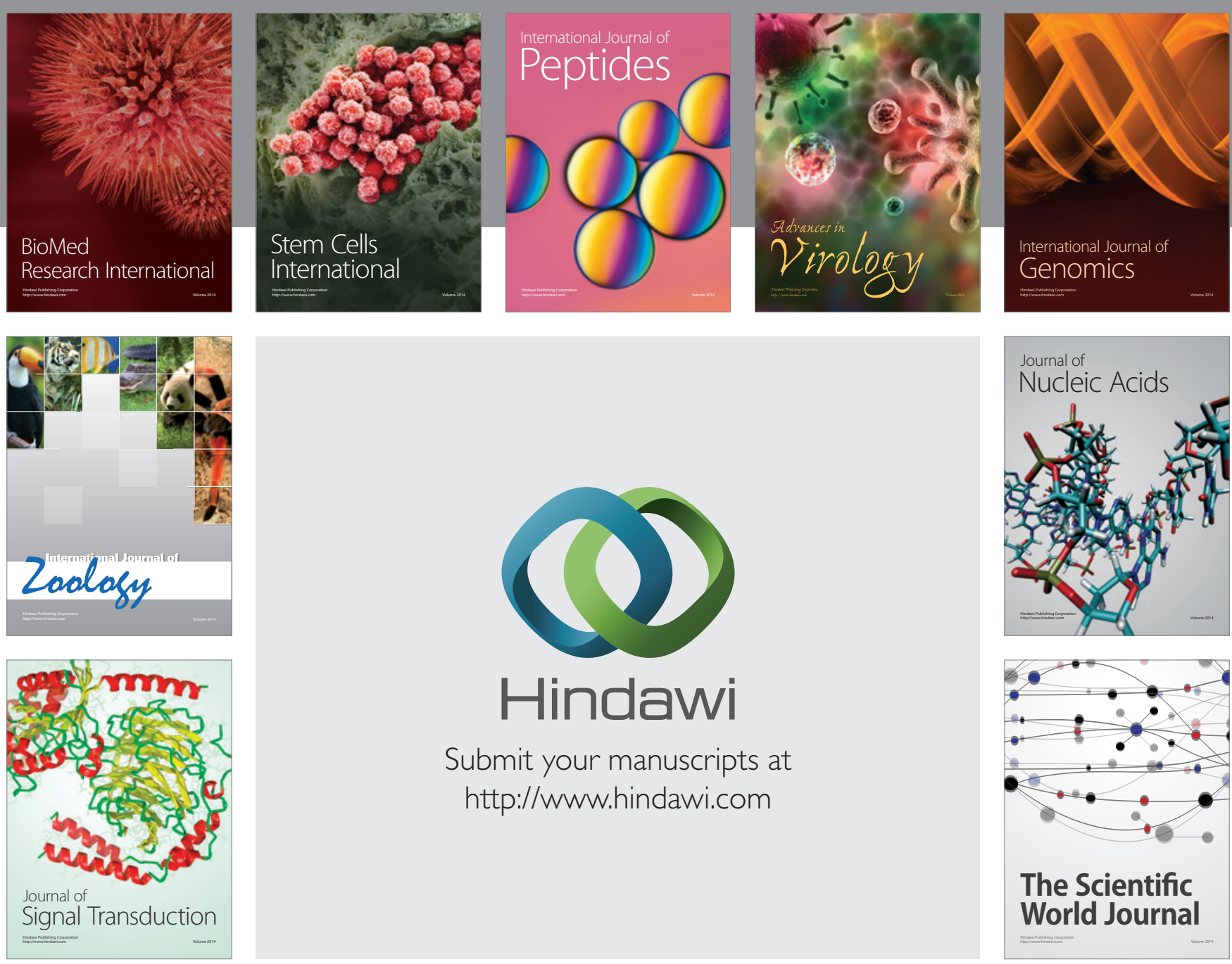

Submit your manuscripts at

http://www.hindawi.com
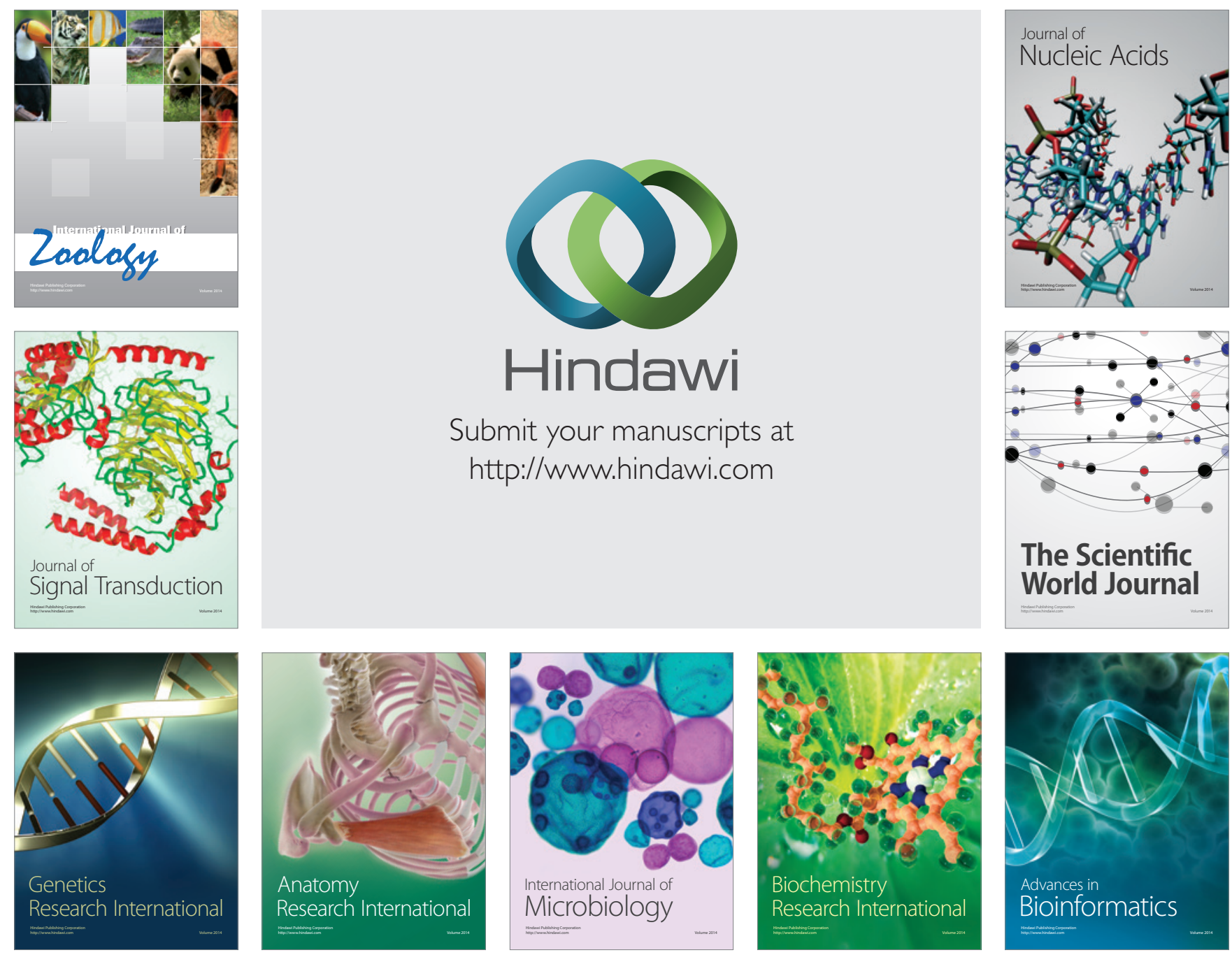

The Scientific World Journal
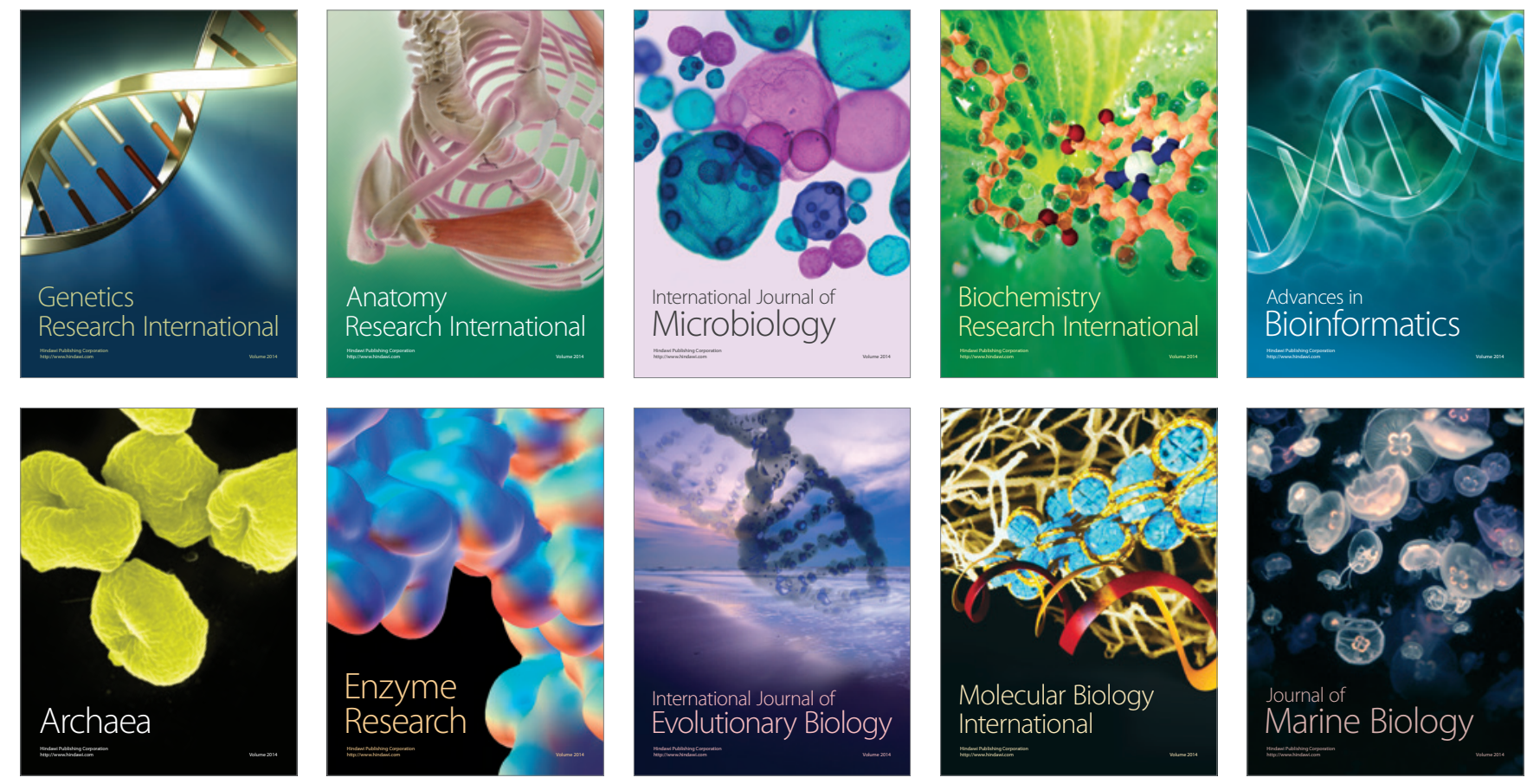